\title{
SURVEI TENTANG PENERAPAN MATA KULIAH PENDIDIKAN INKLUSI PADA SEMUA PROGRAM STUDI DI FKIP UNVERSITAS LAMBUNG MANGKURAT
}

\author{
Husnul Istiqomah \\ Pendidikan Khusus, Fakultas Keguruan dan Ilmu Pendidikan, Universitas Lambung Mangkurat \\ husnulistiqomahazizah@gmail.com
}

\begin{abstract}
Abstrak :
Pendidikan inklusi mencerminkan pendidikan adalah hak semua anak. Ilmu Pendidikan inklusi atau sebidangnya menjadi pengaruh penting dalam pergerakannya pada Perguruan tinggi yang menjadi salah satu penentu kualitas Pendidikan Inklusi pada dunia pendidikan. Perguruan tinggi berperan untuk penentu kesiapan peserta didik menjadi calon masyarakat yang mempunyai kelebihan pada bidang ilmu pengetahuan. Adapun tujuan dari penelitian adalah melihat hasil bagaimana penerapan dari bekal mata kuliah pendidikan inklusi di FKIP, ULM dalam pemahaman, implementasi dan pemberian layanan pendidikan saat terjun menghadapi peserta didik anak berkebutuhan khusus. Penelitian ini menggunakan pendekatan kuantitatif untuk meng menjelaskan suatu penelitian yang hasilnya dapat digeneralisasikan dengan menggunakan metode survei. Hasil dari penerapan mata kuliah pendidikan inklusi pada seluruh program studi termasuk dalam kategori "Sangat baik" dengan presentase keseluruhan berjumlah 76,5\%.
\end{abstract}

Kata Kunci: Pendidikan Inklusi, FKIP

\begin{abstract}
:
Inclusive education reflects education is the right of all children. Inclusive Education or its field has become an important influence in its movement on tertiary institutions which are one of the determinants of the quality of inclusive education in the world of education. Higher education has a role in determining the readiness of students to become prospective people who have advantages in the field of science. The purpose of this research is to see the results of how the application of inclusive education courses in FKIP, ULM in understanding, implementing and providing educational services when engaging students with special needs children. This study uses a quantitative approach to explain a study whose results can be generalized using survey methods. The results of the application of inclusive education courses in all study programs are included in the "Very Good" category with an overall percentage of 76.5\%.
\end{abstract}

Keywords: Inclusive Education, FKIP

\section{PENDAHULUAN}

Pada 2020, penggemboran pemenuhan hak kesamarataan dalam kesempatan mendapatkan pendidikan untuk semua orang semakin nampak. Hal ini dengan segala upaya yang tak lelah dilakukan oleh pemerintah untuk pelaksanaannya (Lestari dkk, 2017). Menurut Dewi (2017) Pendidikan inklusi menjadi salah satu solusi untuk mewujudkan cita-cita penyamarataan hak dalam dunia pendidikan, pendidikan inklusi mencerminkan pendidikan adalah hak semua anak. Konsep dari pendidikan inklusi sendiri menurut Ilahi (2013) adalah 
rancangan dari sebuah pendidikan yang menrepresentasikan ketersedian dalam menerima tanpa terkecuali yaitu peserta didik anak berkebutuhan khusus untuk memperoleh hak dasar sebagai warga negara. Hal ini didukung dengan pendidikan merupakan hak setiap warga negara, tidak terkecuali mereka yang menyandang disabilitas sekalipun (Utomo, 2015).

Ilmu Pendidikan inklusi atau sebidangnya yang terkait dengan inklusi menjadi pengaruh penting dalam pergerakannya. Hal ini menjadi hal yang mendasar bahwa mahasiswa harus memahami bahwa pendidikan inklusi merupakan sesuatu bekal yang sangat penting. Menurut (Yuwono, 2017) kepedulian terhadap suatu ekuitas dan pengembangan kualitas pendidikan melalui sistem pendidikan inklusif diharapkan untuk mengakomodasi kebutuhan pendidikan di masyarakat. Hal ini didukung menurut Harvey dkk (2008) bahwa bekal pendidikan inklusi diperlukan dan harus disediakan untuk calon pendidik. Kemudian didukung oleh Hermanto (2008) menurutnya dengan adanya program penyelenggaraan inklusi, maka guru akan mendapatkan kemampuan lebih mengidentifikasi peserta didik dan atau calon peserta didik termasuk adanya anak-anak berkebutuhan khusus.

Pendidikan inklusi dewasa ini masih perlu banyak pembenahan sebagai perannya dalam pendidikan mengingat masalah yang masih dihadapi, tantangan yang terus belanjut dalam penerapannya selalu menjadi salah satu kendala dalam ketercapaiannya. walaupun perjalanan bisa dikatakan sudah beberapa tahun. Secara kuantitas dari lembaga pendidikan mengalami peningkatan, namun pemahaman akan pendidikan khusus kualitas masih perlu dipertanyakan (Utomo, 2013). Maka dari itu peran ilmu Pendidikan Inklusi pada perguruan tinggi menjadi andil penting untuk menjadi jawaban tersebut. Keberhasilan penyelenggaraan pendidikan inklusif akan bergantung pada kerjasama baik pemerintah, guru, masyarakat maupun orang tua secara bersama-sama (Saputra, 2016). Maka dari itu peran perguruan tinggi menjadi salah satu penentu kualitas Pendidikan Inklusi dalam dunia pendidikan. Menurut Hermanto (2011) bahwa peningkatan kualitas sistem pendidikan guru di Indonesia harus terus diupayakan guna mencapai sistem pendidikan guru yang lebih efektif dan efisien. Dengan demikian pembaharuan materi mata kuliah harus selalu disesuaikan dengan keadaan dimensi yang berkembang dimasyarakat dan kewajiban tuntutan pendidikan.

Mata kuliah yang dijalani selama perkuliahan bertujuan untuk bekal mengosong dan membuktikan bahwa output mahasiswa pada perguruan tinggi tersebut berkualitas dan didapuk untuk siap mengaplikasikannya nanti dalam pengabdian memberikan ilmu pendidikan pada masyarakat (Maghfirah, 2018). Maka dari itu mata kuliah pendidikan inklusi diperlukan dalam perguruan tinggi. Hal ini didukung oleh Zakia (2015) bahwa Salah satu hal yang mempengaruhi mutu dari pendidikan inklusi adalah kualitas tenaga pendidik. 
Di perguruan tinggi pada Universitas Lambung Mangkurat khususnya fakultas yang berkaitan dengan pendidikan adalah fakultas keguruan dan ilmu pendidikan atau yang sering disingkat dengan FKIP. Pada FKIP terdiri dari beberapa program studi yang berjumlah 21 program studi yaitu PG-SD (Pendidikan Guru Sekolah Dasar), PG-PAUD (Pendidikan Guru Pendidikan Anak Usia Dini), Pendidikan Kimia, Pendidikan Biologi, Pendidikan Fisika, Pendikan Pancasila dan Kewarganegaraan, Pendidikan Khusus, Pendidikan Sosiologi dan Antropologi, Pendidikan Ekonomi, Pendidikan Sejarah, Pendidikan Ilmu Pendidikan Sosial, Pendidikan Ilmu Komputer, Pendidikan Ilmu Pengetahuan Alam, Pendidikan Bahasa Inggris, Pendidikan Geografi, Pendidikan Seni Tari dan Musik, Pendidikan Bahasa dan Sastra Indonesia, Pendidikan Matematika, Bimbingan Konseling, Teknologi Pendidikan dan Pendidikan Jasmani.

Menurut Yuliawati (2018) Perguruan tinggi berperan menyiapkan pribadi peserta didik menjadi warga masyarakat yang memiliki kelebihan dalam ilmu pengetahuan. FKIP sendiri mengingat berlatar belakang pendidikan maka pada idealnya harus mampu menghadapi tantangan apapun untuk pembuktian mahasiswa yang berkualitas dan siap diterjunkan pada berbagai ranah pendidikan, baik pendidikan dengan sekolah reguler, sekolah inklusi dan SLB (Sekolah Luar Biasa) (Maghfiroh, 2018).

Menurut Sulistyorini (2018). Perguruan tinggi berperan dalam menentukan pemerataan pendidikan bagi semua kalangan tidak terkecuali peserta didik berkebutuhan khusus dengan pendidikan inklusif.

Pembahasan penilitan ini adalah penerapan mata kuliah pendidikan inklusi yang telah didapatkan pada proses perkuliahan di FKIP, ULM. Hasil dari penerapan ini dapat kita ketahui bagaiamana ketercapaian tujuannya dan pembekalan yang diterima oleh mahasiswa. Menurut Amka dan Kusumastuti (2017) dalam penelitiannya pendidikan inklusi menjadi faktor penting dalam perbaikan dan pendorong sikap untuk komitmen lebih besar pada tujuannya saat terjun dimasyarakat.

Adapun tujuan penelitian adalah untuk melihat hasil dari bagaimana penerapan bekal mata kuliah pendidikan inklusi oleh mahasiswa dalam pemahaman, implementasi dan pemberian layanan pendidikan saat terjun dilapangan baik itu pada sekolah inklusi maupun Sekolah luar biasa (SLB). 


\section{METODE PENELITIAN}

Pada penelitian ini menggunakan pendekatan kuantitatif untuk menjelaskan atau menggambarkan sebuah penelitian yang dapat digeneralisasikan. Menurut Kriyanto (2008) Pendekatan kuantitatif memiliki aspek keleluasaan data sehingga mendapatkan hasil yang representasi.

Metode penelitian yang digunakan adalah metode survei. Menurut Kriyanto (2008) survei adalah penelitian menggunakan kuisioner sebagai acuan instrumen untuk pengumpulan data yang bertujuan untuk mendapatkan informasi dari responden. Penelitian ini mengumpulkan informasi menggunakan kuesioner yang dibagikan kepada responden. Survei merupakan sebuah penelitian yang menggunakan kuesioner sebagai pengumpulan data yang diambil dari sampel suatu populasi (Singarimbun, 2002).

Adapun subjek penelitian ini adalah mahasiswa FKIP yang telah menerima mata kuliah pendidikan inklusi berjumlah 21 orang yang masing-masing mewakili 21 program studi.

Pengumpulan data pada penelitian ini adalah dengan kuisioner. Penelitian ini berjumlah sebanyak 10 buah pertanyaan. Pada aspek pemahaman, sarana prasarana dan tanggapan lanjutan mata kuliah Pendidikan Inklusi dengan variabel X.

\section{Teknik Analisis Data}

Data yang telah didapatkan kemudian dianalisis menggunakan skala likert yang kemudian akan dicari hasil presentase.

Tabel 1. Skala Likert

\begin{tabular}{|c|c|c|}
\hline No & Penilaian & Score \\
\hline 1 & SS & 4 \\
\hline 2 & S & 3 \\
\hline 3 & TS & 2 \\
\hline 4 & STS & 1 \\
\hline
\end{tabular}

Tabel 1. Skala likert digunakan sebagai penscoran data yang didapat dari responden dengan keterangan :

SS : Sangat Setuju

S : Setuju

TS : Tidak Setuju

STS : Sangat Tidak Setuju 
Tabel 2. Tingkat Capaian Responden

\begin{tabular}{|c|c|c|}
\hline No & Presentase pencapaian & Interprestasi \\
\hline 1 & $76-100 \%$ & Sangat Baik \\
\hline 2 & $56-75 \%$ & Baik \\
\hline 3 & $40-55 \%$ & Cukup \\
\hline 4 & $0-39 \%$ & Kurang Baik \\
\hline
\end{tabular}

Tabel 2.Tingkat capaian responden sebagai acuan ketercapian hasil

\section{HASIL DAN PEMABHASAN}

\section{HASIL}

Tabel 1. Hasil Uji Validitas

\begin{tabular}{cccc}
\hline Butir & Nilai Corrected Item Total Correlation/ & Kriteria \\
& $r_{\text {hitung }}$ & $r_{\text {hitung }}$ & \\
\hline 1 & 0,532 & 0,433 & Valid \\
2 & 0,621 & 0,433 & Valid \\
3 & 0,618 & 0,433 & Valid \\
4 & 0,461 & 0,433 & Valid \\
5 & 0,548 & 0,433 & Valid \\
6 & 0,731 & 0,433 & Valid \\
7 & 0,488 & 0,433 & Valid \\
8 & 0,617 & 0,433 & Valid \\
9 & 0,613 & 0,433 & Valid \\
10 & 0,604 & 0,433 & Valid \\
\hline
\end{tabular}

Pengambilan keputusan berdasarkan nilai $r_{\text {hitung }}>r_{\text {Tabel }}$ sebesar 0,433 , untuk $\mathrm{df}=21$; $\alpha=0,05$. Didapatkan hasil valid.

Tabel 2. Uji Reliabel

Reliability Statistics

\begin{tabular}{|r|r|}
\hline $\begin{array}{c}\text { Cronbach's } \\
\text { Alpha }\end{array}$ & N of Items \\
\hline, 774 & 10 \\
\hline
\end{tabular}

Tabel 2. Uji reabilitas akan dilakukan pada butir pertanyaan yang sudah valid. Suatu variabel akan diakatakan reliabel jika jawaban konsisten.

Hasil nilai "Aplpha Cronbach" $>0.600$. 
Tabel 3. Hasil Score, Mean dan TCR

\begin{tabular}{|c|c|c|c|c|}
\hline Butir & N & Score & Mean & TCR \\
\hline 1 & 21 & 74 & 3,52 & 88,1 \\
2 & 21 & 64 & 3,05 & 76,2 \\
3 & 21 & 68 & 3,24 & 81,0 \\
4 & 21 & 70 & 3,33 & 83,3 \\
5 & 21 & 60 & 2,86 & 71,4 \\
6 & 21 & 68 & 3,24 & 81,0 \\
7 & 21 & 56 & 2,67 & 66,7 \\
8 & 21 & 53 & 2,52 & 63,1 \\
9 & 21 & 67 & 3,19 & 79,8 \\
10 & 21 & 63 & 3,00 & 75,0 \\
\hline \multicolumn{5}{|r}{ Mean } \\
\hline
\end{tabular}

Tabel 3. Hasil Score merupakan perolehan dari jumlah score penilaian dari butir instrumen. Mean kesuluruhan berjumlah 3,06 dengan TCR akhir 76,5\%.

$\mathrm{N}=$ Jumlah Responden

\section{PEMBAHASAN}

Hasil dari penerapan mata kuliah pendidikan inklusi pada seluruh program studi mendapatkan kategori "sangat baik" yang dapat dilihat dari hasil presentase keseluruhan berjumlah 76,5\%. Pada mata kuliah pendidikan inklusi dapat membantu mahasiwa untuk memahani peserta didik anak berkebutuhan khusus mendapatkan presentase yang besar yaitu 88.1\% yang dikategorikan "sangat baik". Materi mata kuliah pendidikan inklusi mudah dipahami 76,2\% "sangat baik". Materi ajar perkuliahan mata kuliah pendidikan inklusi 81,1\% “sangat baik". Dosen pengampu mata kuliah pendidikan inklusi kompeten 83,3\% "sangat saik". Layanan staf kebersihan/penjaga ruangan perkuliahan mata kuliah pendidikan inklusi 71,4\% “baik”. Ruangan perkuliahan ramah disabilitas 81.0\% “sangat baik”. Adanya proses pembelajaran kelas gabungan 66,7\% “baik”. Proses perizinan observasi/praktik mata kuliah pendidikan inklusi 63,1\% "baik". Evaluasi lanjutan silabus materi mata kuliah pendikan inklusi 79,8\% “sangat baik”. Adanya kelanjutan mata kuliah pendidikan inklusi 75,0\% “sangat baik”. Agar mudah dipahami peneliti membagi variabel manjadi 3 aspek yaitu pemahaman, sarana prasarana dan tanggapan kelanjutan mengenai penerapan mata kuliah pendidikan inklusi. 


\section{Pemahaman}

\section{Mata kuliah pendidkan inklusi dapat membantu mahasiswa untuk memahami peserta} didik anak berkebutuhan khusus.

Mata kuliah pendidikan inklusi mendapat presentase sebesar 88\% dengan kategori "sangat baik". Hasil ini yang didapat bahwa mahasiswa merasa terbantu dengan adanya mata kuliah pendidikan inklusi yang telah dijalankan. Dengan adanya pemahaman pada calon pendidik akan mempermudah dalam implementasinya. Hal ini didukung dengan Pratiwi (2016) bahwa mengembangkan pendidikan inklusi adalah suatu alternative untuk mengurangi tantangan dalam penyelenggaraan sekolah inklusi. Mengingat bahwa alumni dari lulusan FKIP notaben akan berkecimpung pada belajar mengajar sekolah inklusi. Dengan adanya pemahaman dari calon pendidik kepada peserta didik anak berkebutuhan khusus akan memperkokoh untuk menumbuhkan komitmen, pengetahuan dan bekal yang akan ditampilkan pada masyarakat. Hal ini juga bertujuan untuk meningkatkan kesadaran calon pendidik dalam mengembangkan sekolah inklusi (Pratiwi, 2016). Dengan adanya pemahaman mengenai pendidikan inklusi maka calon pendidik akan mudah untuk melakukan penanganan dan layanan terhadap peserta didik, baik dalam menemukenali atau identifikasi maupun program lanjutan layanan pendidikan hak anak. Hal ini didukung oleh Yuwono (2015) bahwa identifikasi bertujuan menemukenali peserta didik anak berkebutuhan khusus yang memerlukan untuk mendapatkan layanan pendidikan melalui progam pendidikan inklusi.

\section{Materi mata kuliah pendidikan inklusi mudah dipahami.}

Materi mata kuliah Pendidikan Inklusi mudah dipahami mendapatkan presentase 76,2\% dengan kategori "Sangat Baik". Dengan adanya hasil bahwa materi mata kuliah pendidikan inklusi ini mudah dipahami menunjukkan bahwa pemahaman mahasiswa mengenai peserta didik anak berkebutuhan khusus sangat baik. Mata kuliah pendidikan inklusi membahas hal mengenai pelayanan anak berkebutuhan khusus hingga bagaimana sekolah inklusi. Hasil ini didukung dengan penelitian oleh Maghfirah (2018) bahwa mata kuliah pendidikan inklusif menambah, pengalaman, serta semakin berkembangnya rasa dalam memberlakukan pesera didik anak berkebutuhan khusus. Dengan mata kuliah pendidikan inklusi calon pendidik akan mampu dan tahu dalam memahami peserta didik anak berkebutuhan khusus (Maghfirah, 2018).

\section{Materi ajar perkuliahan Mata Kuliah Pendidikan inklusi}

Materi ajar perkuliahan Mata Kuliah Pendidikan inklusi dengan presentase "81,1" dengan kriteria "Sangat Baik". Dari hasil tersebut yang didapatkan mahasiswa bahwa Dosen 
memberikan bahan ajar materi perkuliahan pendidikan inklusi kepada mahasiswa pada proses pembelajaran. Materi ajar yang diberikan sesuai dengan silabus yang sudah dirancang sebelumnya oleh dosen pengampu. Materi ajar sendiri diharapkan untuk menambah pemahaman mahasiswa mengenai peserta didik anak berkebutuhan khusus agar tujuan perkuliahan yang telah direncanakan sesuai dengan tujuan pembelajaran yang telah ditentukan (Maghfirah, 2018).

\section{Dosen pengampu mata kuliah pendidikan inklusi kompeten}

Perkuliahan pada mata kuliah pendidikan inklusi di FKIP didukung dengan dosen yang kompeten. Ini terbukti dengan hasil bahwa dosen pengampu kompeten dalam proses belajar mengajar mendapat presentase sebanyak 83,3\% dengan kriteria "Sangat Baik". Dengan pengajar yang kompeten mahasiswa mudah menerima dan memahami mata kuliah pendidikan inklusi sehingga apa tujuan dari pendidikan inklusi tersebut tercapai. Dengan ketercapaian yang baik maka semakin baik implementasi calon pendidik dalam penyelenggraan sekolah inklusi. Dengan dosen pengampu yang kompeten maka penyelenggaraan pendidikan inklusi akan tercapai. Hal ini didukung oleh Purwandari (2009) bahwa perguruan tinggi memiliki peran serta penyelengraraan sekolah inklusif khususnya dalam penyediaan SDM tenaga kependidikan.

Hasil pendapat dan penelitian dari berbagai ahli pendidikan adalah bagaimanapun kebijakan yang telah diterapkan, seperti kurikulum yang berbasis kompetensi, sarana dan prasara yang disediakan dan pengembangan sekolah yang sudah baik, tetap yang akan menjadi penentu sebuah keberhasilan pendidikan pada sebuah sekolah tersebut adalah tenaga pendidik (Matnuh, 2017).

\section{Sarana dan Prasarana}

\section{Layanan staf kebersihan/penjaga ruangan perkuliahan mata kuliah pendidikan inklusi}

Layanan staf kebersihan/penjaga ruangan perkuliahan mata kuliah pendidikan inklusi mendapat presentase $71,4 \%$ dengan kriteria "Baik". Hal tersebut menunjukkan bahwa layanan staf kebersihan/penjaga ruangan melaksanakan tugasnya dengan baik mengingat kebersihan mempengaruhi keberhasilan mahasiswa dalam pemahaman materi ajar yang diberikan. Hal ini didukung oleh Subagio (2018) bahwa kebersihan sangat berpengaruh pada kelangsungan efektifitas belajar karena kebersihan menimbulkan kesadaran mahasiswa untuk berperilaku baik dikampus (Sembiring 2015). Menurut Melania (2017) Kinerja layanan yang baik menimbulkan peningkatan kepuasan mahasiswa. Menurutnya tidak ada salahnya jika diperlukan perbaikan menyeluruh lagi agar kinerja layanan bisa ditingkatkan lebih lagi. 


\section{Ruangan perkuliahan ramah disabilitas}

Ruangan perkuliahan ramah disabilitas mendapat 81.0\% dengan kriteria "Sangat baik". Hal ini mengacu pada ruangan yang digunakan untuk perkuliahan pada mata kuliah pendidikan inklusi. Menurut Amka (2019) Dukungan untuk pembelajaran yang berhasil secara inklusif dapat dilihat dari bagaimana kesiapan dalam hal-hal lembaga untuk menerapkan sistem layanan pendidikan inklusi dapat dilihat dari sarana dan prasarananya (Pratiwi 2016). Namun dari hasil yang didapat tidak senada dengan penelitian Utomo dan Suratno (2019) bahwa aksesibilitas lingkungan di Universitas Lambung Mangkurat dinyatakan bahwa masih banyak bangunan (fasilitas khusus atau fasilitas umum) yang tidak sesuai dengan spesifikasi aksesibilitas teknis. Aksesibilitas merupakan suatu kebutuhan yang penting bagi disabilitas. Karena dengan aksesiblitas, disabilitas akan dapat melakukan mobilitas (Thohari 2017)

\section{Adanya proses pembelajaran kelas gabungan}

Hasil dari adanya proses pembelajaran kelas gabungan mendapatkan presentase berjumlah 66,7\% dengan kriteria "Baik". Berhubung mata kuliah pendidikan inklusi merupakan mata kuliah fakultas maka dilaksanakan kelas gabungan antar prodi. Pada hal ini terlihat bahwa mahasiswa menampilkan kerjasama yang baik. Hal ini didukung dengan penelitian Maghfirah (2018) bahwa terdapat hubungan pendidikan inklusif dengan Semua program studi. Ini mendukung bahwa hubungan yang baik akan menciptakan tujuan inklusi yang akan dicapai.

\section{Tanggapan kelanjutan}

\section{Proses perizinan observasi/praktik lapangan mata kuliah pendidikan inklusi}

Observasi, sebagai sebuah pilihan metode dalam mengembangkan dan menemukan informasi secara lebih luas (Hasanah, 2017). Adanya observasi pada perkuliahan diharapkan meningkatkan pemahaman mahasiswa pada pembelajaran pendidikan inklusi. Dari hasil yang didapat proses perizinan observasi untuk mata kuliah pendidikan inklusi 63,1\% dengan kriteria "Baik". Perizinan sendiri dilaksanakan untuk kelancaran dalam menghimpun informasi, yanng diharapkan akan menambah pengetahuan mahasiswa. Selain itu observasi atau praktik pengalaman lapangan dapat lebih mudah bergaul dengan para guru, staff, dan peserta didik serta mampu menunjukkan bahwa sebagai pribadi dewasa, pandai, jujur, dan beradab serta bertindak sesuai dengan norma yang berlaku (Hapsari, 2016). Namun menurut Jabar berpendapat bahwa bagaimanapun menyiapkan guru supaya bisa memahami konsep dan praktek pendidikan inklusif tidak bisa secara cepat diimbaskan kepada guru di lapangan. 


\section{Evaluasi lanjutan silabus mata kuliah pendidikan inklusi}

Evaluasi lanjutan silabus materi mata kuliah pendikan inklusi mendapatkan hasil 79,8\% dengan kriteria "Sangat baik". Hal ini sependapat bahwa silabus memerlukan adanya evaluasi lagi untuk pembaharuan baik itu materi ajar maupun ketercapaiannya. Kurikulum adalah sebuah landasan untuk berdiri. Fungsi dasarnya adalah menunjukkan arah tujuan yang akan dicapai dan juga sebagai sebuah landasan (Bahri, 2017). Silabus adalah acuan ketercapaian yang didinginkan dalam pembelajaran. Untuk itu ini adalah tuntutan oleh calon pendidik senada dengan Johnsen dkk (2003) bahwa ini bertujuan untuk upaya menuntut adanya pergeseran dalam paradigma mengenai pembelajaran pada sekolah inklusi yang masih kurang sesuai. Menurut Yuwono (2017) Evaluasi program merupakan suatu proses. Secara jelas bahwa evaluasi adalah membandingkan antara yang telah dicapai dan diperoleh dengan program yang seharusnya dicapai sesuai dengan standar. Evaluasi memiliki peran sebagai kontrol pada sebuah program guna mengukur ketercapaian tujuan dari suatu program dan implementasinya. Hal yang sering terjadi pada evaluasi adalah bagaimana caranya untuk meningkatkan (to improve) dan membuktikan (to prove). Tahapan pengkajian sebuah evaluasi program dapat serupa dengan sebuah penelitian ilmiah (research) yang banyak dilakukan oleh kalangan mahasiswa. Menurut Yuwono (2018) pendidikan inklusif adalah penyedia layanan. Implementasi modifikasi kurikulum ini dilihat dari empat indikator yang mengacu pada implementasi kurikulum inklusif.

\section{Kelanjutan mata kuliah pendidikan inklusi}

Hasil yang didapat mengenai kelanjutan mata kuliah pendidikan inklusi mendpat 75,0\% dengan kriteria "Sangat baik". Hal ini menunjukkan bahwa mahasiswa antusias untuk pelaksanakaan mengenai memahami peserta didik anak berkebutuhan khusus. Pembekalan mendalam menjadi nilai tambah mahasiswa dalam memahami peserta didik anak berkebutuhan khusus. Hal ini sependapat dengan dari hasil penelitian menurut Jabar bahwa dari segi penyiapan guru, perlu pembenahan lagi yang memerlukan banyak energi dan waktu. Perlu pengorbanan yang besar dalam persiapan guru karena pemahaman disiapkan secara terspesialisasi pada perguruan tinggi. Hal ini tentunya bertujuan untuk bekal mengidentifikasi proses layanan dan pembelajaran dalam mengembangkan dan membina peserta didiknya dengan baik (Hermanto 2018). 


\section{PENUTUP}

\section{Simpulan}

Hasil dari penelitian yang telah dilakukan. Peneliti membuat 3 aspek bahasan pada variabel agar mudah dipahami yaitu mengenai pemahaman, sarana dan prasarana beserta tanggapan kelanjutan mengenai adanya penerapan mata kuliah pendidikan inklusi pada seluruh program studi diFKIP, ULM.

Hasil dari penerapan mata kuliah pendidikan inklusi pada seluruh program studi termasuk dalam kategori "sangat baik" dilihat dari hasil presentase keseluruhan berjumlah 76,5\%. Pada mata kuliah pendidikan inklusi dapat membantu mahasiwa untuk memahani peserta didik anak berkebutuhan khusus mendapatkan presentase yang besar yaitu $88.1 \%$ yang dikategorikan "sangat baik". Materi mata kuliah pendidikan inklusi mudah dipahami 76,2\% "sangat baik". Materi ajar perkuliahan mata kuliah pendidikan inklusi didapatkan mahasiswa "81,1" "sangat baik". Dosen pengampu kompeten 83,3\% "sangat baik". Layanan staf kebersihan/penjaga ruangan perkuliahan pendidikan inklusi $71,4 \%$ "baik". Ruangan perkuliahan ramah disabilitas $81.0 \%$ "sangat baik". Adanya proses pembelajaran kelas gabungan 66,7\% "baik". Proses perizinan observasi mata kuliah pendidikan inklusi 63,1\% “Baik". Evaluasi lanjutan silabus materi mata kuliah pendidikan inklusi 79,8\% "sangat baik". Adanya kelanjutan mata kuliah pendidikan inklusi 75,0\% "sangat baik".

Dari hasil akhir yang telah peneliti dapatkan bahwa penerapan mata kuliah pendiikan inklusi mendapat presentase sebanyak 76,5\% dengan kategori sangat baik. Penerapan mata kuliah pendikan inklusi dilaksanakan dengan baik pada seluruh program studi di FKIP, ULM. Namun dengan hasil yang telah didapat diharapkan untuk terus meningkatkan kualitas pengajaran maupun pelaksaanya demi mendukung kampus yang inklusif dan pembekalan pengajaran terhadap calon pendidik terhadap peserta didik anak berkebutuhan khusus.

\section{Saran}

Berdasarkan pembahasan hasil penelitian ada hal-hal yang dapat disarankan:

1. Pihak penyelenggara inklusi kampus

Meningkatkan kinerja lebih lagi dalam pelaksaannya baik itu proses pembelajran, sarana dan prasarana hingga ketercapian tujuan untuk membangun pendidikan yang inklusi.

2. Dosen

Hasil ini diharapkan menjadi motivasi lebih dalam pengembangan dan upaya untuk ketercapaian pendidikan inklusi. Dosen yang bukan pengampu mata kuliah pendiikan 
inklusi diharapkan peneliti untuk membantu dan mendukung penyelenggaraan inklusi dengan menerapkan beberapa prinsif inklusi dalam mata kuliah yang lain.

3. Bagi peneliti selanjutnya

Peneliti sendiri sadari hasil dari penelitian ini masih memiliki keterbatasan dalam pengumpulan data dan penggalian pembahasan. Untuk itu peneliti harapkan penelitian yang lebih lanjut untuk mendapatkan pembahasan dan data yang lebih dalam lagi. Hasil ini diharapkan untuk digunakan sebagai bahan rujukan atupun referensi untuk penelitian yang lanjutan yang lain.

4. Bagi peneliti

Sebagai calon pendidik nantinya, peneliti akan mengimplementasikan pendidikan inklusi dengan baik kelak. Agar menjadi salah satu bukti untuk mendukung dalam penyelenggaraan pendidikan inklusi disekolah.

\section{DAFTAR PUSTAKA}

Amka, A. 2017. Implementasi Pendidikan Karakter Inklusi Bagi Anak Berkebutuhan Khusus Di Sekolah Reguler. Madrosatuna: Journal of Islamic Elementary School, 1(1), 1-12.

Amka, A., \& Kusumastuti, D. E. 2019. The Level of Support For Successful Learning in Inclusive Primary School in Banjarmasin. Journal of ICSAR, 3(2).

Ariastuti, R., \& Herawati, V. D. 2016. Optimalisasi peran sekolah inklusi. Jurnal Pengabdian Pada Masyarakat, 1(1), 38-47.

Aziz, Y. 2011. Penguatan Mata Kuliah Pendidikan Agama Islam di Perguruan Tinggi Umum. Jurnal Sosial Humaniora, 4(2), 145-163.

Bahri, S. 2017. Pengembangan Kurikulum Dasar dan Tujuannya. Jurnal Ilmiah Islam Futura, 11(1), 15-34.

Chanifah, N. 2015. Desain Pendidikan Karakter di Perguruan Tinggi Umum. In Seminar Nasional Riset Inovatif (Vol. 3).

Dewi, N. K. 2017. Manfaat Program Pendidikan Inklusi untuk AUD. Jurnal Pendidikan Anak, 6(1), 12-19.

Hamzah, S. H. 2012. Aspek Pengembangan Peserta Didik: Kognitif, Afektif, Psikomotorik. Dinamika Ilmu, 12(1).

Hermanto, S. P. 2011. Penambahan Program Wajib Kokurikuler Sebagai Redesain Sistem Pendidikan Guru. Makalah: FIP UNY.

Hermanto, H. 2008. Kemampuan guru dalam melakukan identifikasi anak berkebutuhan khusus di sekolah dasar penyelenggara pendidikan inklusi. Yogyakarta State University. 
Harvey, M. W., Yssel, N., Bauserman, A. D., \& Merbler, J. B. 2008. Preservice Teacher Preparation for Inclusion. Remedial and Special Education, 31(1), 24-33. doi:10.1177/0741932508324397

Hasanah, H. 2017. Teknik-teknik observasi (sebuah alternatif metode pengumpulan data kualitatif ilmu-ilmu sosial). At-Taqaddum, 8(1), 21-46

Hapsari, P., \& Widhianningrum, P. 2016. Pengaruh Praktik Pengalaman Lapangan Terhadap Kinerja Mahasiswa Calon Guru. Journal of Accounting and Business Education, 2(1).

Ilahi, Muhammad Takdir. 2013. Pendidikan Inklusi: Konsep \& Aplikasi. Yogyakarta: ArRuzz Media.

Irvan, M. 2017. Pengetahuan mahasiswa pg-paud unipa surabaya tentang pendidikan inklusif. Buana Pendidikan: Jurnal Fakultas Keguruan dan Ilmu Pendidikan, 13(24), 155-164.

Jabar, C. S. A. Pendidikan Inklusif: Mungkinkah Mengambil Alih Peran Pendidikan Luar Biasa?.

Johnsen B.H. \&Skjorten MD. 2003. Menuju Inklusi, Pendidikan Kebutuhan Khusus Sebuah Pengantar. Bandung. Program Pasca Sarjana UPI Bandung.

Kriyantono, Rakhmat. 2008. Teknik praktis riset komunikasi. Jakarta: Kencana Prenada Media Group

Lazwardi, D. 2017. Manajemen kurikulum sebagai pengembangan tujuan pendidikan. $A l$ Idarah: Jurnal Kependidikan Islam, 7(1), 119-125.

Lestari, E. Y., Sumarto, S., \& Isdaryanto, N. 2017. Pemenuhan hak bagi penyandang disabilitas di kabupaten Semarang melalui implementasi convention on the rights of persons with disabillities (CPRD) dalam bidang pendidikan. Integralistik, 28(1), 1-9.

Maghfirah, M. 2018. Pendidikan Inklusi dan Perguruan Tinggi: Urgensi Penerapan Matakuliah Pendidikan Inklusi pada Semua Program Studi Jurusan Tarbiyah STAIN Pamekasan. Vol. 13. No.1

Matnuh, H. 2017. Perlindungan Hukum profesionalisme Guru. Jurnal Pendidikan Kewarganegaraan, 7(2), 46-50.

Melania, M. 2017. Analisis Kualitas Pelayanan Tenaga Administratif Kampus 2 Stie Pancasetia. Kindai, 13(1).

Noor, I. H. 2010. Penelitian dan pengabdian masyarakat pada perguruan tinggi. Jurnal Pendidikan Dan Kebudayaan, 16(3), 285-297.

Nulhaqim, S. A., Heryadi, D. H., Pancasilawan, R., \& Ferdryansyah, M. 2016. Peranan Perguruan Tinggi dalam Meningkatkan Kualitas Pendidikan di Indonesia untuk Menghadapi ASEAN Community 2015 Studi Kasus: Universitas Indonesia, Universitas Padjadjaran, Institut Teknologi Bandung. Share: Social Work Journal, 6(2), 197. 
Pratiwi, J. C. 2016. Sekolah inklusi untuk anak berkebutuhan khusus: tanggapan terhadap tantangan kedepannya. Prosiding Ilmu Pendidikan, 1(2).

Purwandari. 2009. Pendidikan Inklusif: Masalah ketenagaan dan peran serta perguruan tinggi dalam penyelenggaraan sekolah inklusi. Universitas Negri Yogyakarta.

Rahayu, S. 2019. Manajemen Sarana dan Prasarana Pendidikan.

Rahmat, A. S. 2014. Model Pengembangan Pendidikan Nilai Di Perguruan Tinggi.

Saputra, A. 2016. Kebijakan Pemerintah terhadap Pendidikan Inklusif. Golden Age: Jurnal Ilmiah Tumbuh Kembang Anak Usia Dini, 1(3), 1-15.

Singarimbun, Masri. 2002. Metode penelitian survei. LP3S: Jakarta.

Sugiyono. 2008. Metode penelitian kuantitatif, kualitatif dan $r \& d$. Bandung: Penerbit Alfabeta.

Sukinah. 2010. Manajemen Strategi Implementasi Pendidikan Inklusi. Vol.7. No.2. Nopember.

Sukoco, F. 2010. Pengaruh pendidikan dan pelatihan, pembelajaran organisasi terhadap kinerja dengan kompetensi sebagai mediasi. Jurnal Bisnis dan Ekonomi, 17(1).

Sulistyorini, S. 2018. Resiliensi Aqidah Komponen Pendidikan dalam Rekonstruksi Eksistensi Pendidikan Inklusi di Perguruan Tinggi.Millah: Jurnal Studi Agama, 17(2), 155-176.

Subagio, S. 2018. Identifikasi Kepedulian Mahasiswa Program Studi Pendidikan Biologi Fpmipa Ikip Mataram Terhadap Kebersihan Ruang Kuliah Dan Pengaruhnya Bagi Efetivitas Belajar. Jurnal Ilmiah IKIP Mataram, 5(1), 13-17.

Sembiring, E. B. 2015. Pengembangan Media Sosialisasi Etika Kampus Dalam Bentuk Animasi 2D. Jurnal Teknomatika, 7(2), 17.

Thohari, S. 2017. Pandangan Disabilitas dan Aksesibilitas Fasilitas Publik bagi Penyandang Disabilitas di Kota Malang. IJDS: INDONESIAN JOURNAL OF DISABILITY STUDIES, 1(1).

Utomo, U. 2013. Meluruskan Implementasi Pendidikan Inklusif.

Utomo, U. 2015. Aksesibilitas Penyandang Disabilitas Menempuh Pendidikan Tinggi.

Utomo, U., \& Suratno, S. 2019. The Accessibility Analysis for The Special Needs Students in Lambung Mangkurat. Journal of ICSAR, 3(2).

Yuliawati, S. 2018. Kajian Implementasi Tri Dharma Perguruan Tinggi sebagai Fenomena Pendidikan Tinggi di Indonesia. Jurnal Ilmiah Widya, 218712. 
Yuwono, I. Membangun Nilai-Nilai Nasionalisme Melaluli Paradigma Pendidikan Inklusi. Universitas Lambung Mangkurat.

Yuwono, I. 2017. Indikator Pendidikan Inklusif.

Yuwono, I. 2015. Penerapan Identifikasi, Asesmen dan Pembelajaran pada Anak Autis Di Sekolah Dasar Inklusif. JRR-Jurnal Rehabilitasi \& Remediasi.

Yuwono, I., Kamil, M., Rahardja, D., \& Abdu, W. J. 2017. The Effect of Guidance and Counseling Programs on the Lear Processes of Visually Impaired High School Students. International Journal of Special Education, 32(4), 877-887.

Yuwono, I. 2017. Evaluasi Pelaksanaan Program Pendidikan Inklusif Sd Di Kota Banjarmasin. Universitas Lambung Mangkurat.

Yuwono, I. 2018. Evaluation of Curriculum Implementation and Curriculum Modifications in Inclusive Schools. In 1st International Conference on Creativity, Innovation and Technology in Education (IC-CITE 2018). Atlantis Press.

Zakia, D. L. 2015. Guru Pembimbing Khusus (Gpk): Pilar Pendidikan Inklusi. Prosiding Ilmu Pendidikan, 1(2). 